\title{
Decision tree for enhancing maintenance activities with drones in the mining business
}

\author{
Madeleine Martinsen ${ }^{1}$, Erik Dahlquist ${ }^{2}$, Anders Lönnermark ${ }^{3}$, Örjan Säker ${ }^{4}$ \\ ${ }^{1} \mathrm{ABB}$ Industrial Automation, Industrial PhD student at MDH, Västerås Sweden, \\ madeleine.martinsen@mdh.se \\ ${ }^{2} \mathrm{MDH}$, Mälardalens University, Västerås Sweden, erik.dahlquist@mdh.se \\ ${ }^{3}$ RISE, Research Institutes of Sweden, Borås Sweden, anders.lonnermark@ ri.se \\ ${ }^{4}$ Epiroc, Rocktec Automation Rock Drills AB, Örebro Sweden, orjan.saker@epiroc.com
}

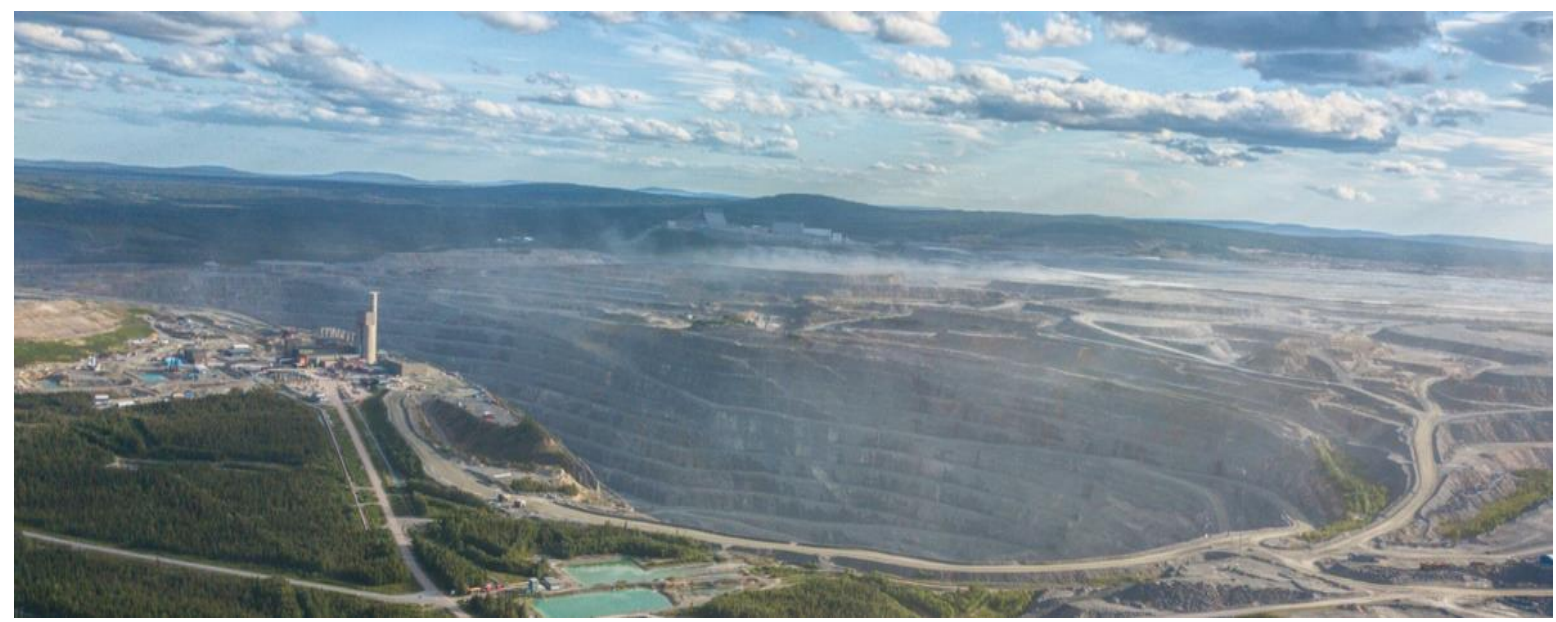

Figure 1. The open pit Aitik, Boliden.

\begin{abstract}
A drone (UAV, unmanned aerial vehicle) is no longer a toy, it is gaining bigger and bigger terrain in the industry as an everyday working tool. Equipped with sensors, thermal cameras, components and system software it most likely will be part of the solutions that continues streamlining the mining operations in the future. Data gathering of signals from sensors mounted on drones and other mining equipment such as mining vehicles creates conditions for monitoring, analysis and warning of possible risks and suggests how these can be avoided in due time. The experimental drone study conducted at an open pit mine Aitik, Boliden (Figure 1) in Sweden will be presented in this paper. Aitik is today the world's most efficient copper $(\mathrm{Cu})$ open pit mine. The authors propose decision trees to support and enable the transformation into a completely autonomous mining operation. In combination with deep learning (DL), pattern recognition and artificial intelligence (AI) applications, creates the puzzle pieces to support mining operations to further increase their productivity and safety.
\end{abstract}

Keywords: maintenance, inspections, drones, mining operations, decision tree, artificial neuron

\section{Introduction}

\subsection{Background}

Metals and minerals are part of our daily lives without them we would not be able to for example use mobiles, brew a cup of coffee or heat dinner in the oven. This makes us dependent on the world's mines. The mining operation consists of several subprocesses like drilling, charging, blasting, loading, crushing, transportation of ore, grinding, flotation, thickening, filtering, drier, smelter, converter as shown in Figure 2. A timeconsuming, expensive and sometime dangerous activity is to conduct maintenance of the entire mining processes consisting of multiple equipment's requiring continuous inspections. Performing maintenance on for example the crusher and the grinding machine demands they are stopped for manually inspections. A job that can take up to a week to perform and is repeated a number of times a year. Such stop entails a cost of roughly 4000 USD per hour when production is at a standstill. In any case, maintenance is an important part to ensure a safe mining operation and maintain a high productivity. In addition, the operation experiences dangerous situation like for example fires resulting in longer production stops. A fire in a mine may cause both deaths and major issues with respect to production that can be very costly. 
Roughly one fire incident occurs per week in the Swedish mines (Hansen, 2011, 2015) with similar frequencies also internationally (Hansen, 2018). $80 \%$ of the fires are caused by mining vehicles (Martinsen et al., 2019). By detecting faulty equipment's such as overheated cables, motors, brakes, pressure changes on tires, oil leakage in engines or hydraulics or similar faults, escalating of fires can be avoided. A further challenge arises when mining production is planned to increase significantly while impairment in productivity or safety is not an option. This is the case for Aitik where production is planned to increase from 36-million-ton ore per year to 45 million ton.

In view of the above stated challenges, the research project aims to evaluate the possibility of introducing drones as a working tool to streamline several of the mining maintenance inspection activities and, if relevant, replace daily duties that are being conducted manually. In addition, the study aims to investigate the possibility of defining decision trees to support fault and root cause analysis from the gathered sensor signals. With the goal to warn, in good time, concerned personnel. Images taken on objects during the drone route and data gathered from sensors attached on the drone and mining equipment's are compared and in the event of deviation from normal operation values, the operators could be warned betimes.

\subsection{Drone application area in the mining industry}

As Figures 3 shows, the market and applications for drones has exploded (Drone Insight Industry, The Drone Market Report 2019-2024). A number of benefits, where companies have introduced drones have been able to demonstrate several advantages such as:

- Time savings

- Enhancement of the productivity

- $\quad$ Supporting the digitization strategy

- Possibility to increase revenue

- Increasing the control and supervision function

- Minimizing manually duties

- Contribute to a safer workplace
This creates curiosity among mining companies to use drones equipped with e.g. IR cameras, gas or other relevant sensors to gather data from these and support the subprocesses like:

- Inspection of power distributions equipment

- Inspection of shafts \& vessels

- Inspection of mine hoist ropes

- Inspection of infrastructure (e.g. roads \& ramps)

- Inspection of equipment e.g. conveyer belts

- Gas measurement after blasting

- Pit and dump management

- Communication and checking daily/weekly plans

- Haul route surface optimizations

- Haul road, dump and pit design

- Up-to-date surfaces for optimized blast designs

- Pre- and post-blast data

- Stockpile management, 3D mapping

- Grade control \& exploration planning

- Drainage and water management

- Watershed, drainage basin, and water flow mapping

- Thermal detection of ground water inflows

- Tailing dams management

- Construction feasibility studies

- Leach pad, dam wall, and platform construction quality control

- Construction progress monitoring \& reporting

- Geophysical \& watershed/catchment area modeling

- Land usage reporting

- Heritage and environmental management

- Erosion detection, Inspection of rock mechanic

- Vegetation change tracking

- Security, corridor, and boundary surveillance

- Trolley equipment for the electrified truck route

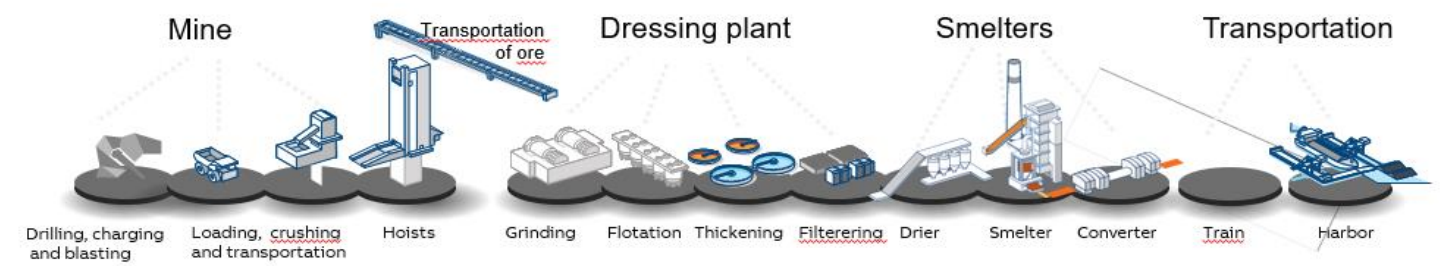

Figure 2. The Mining Process, picture by ABB. 

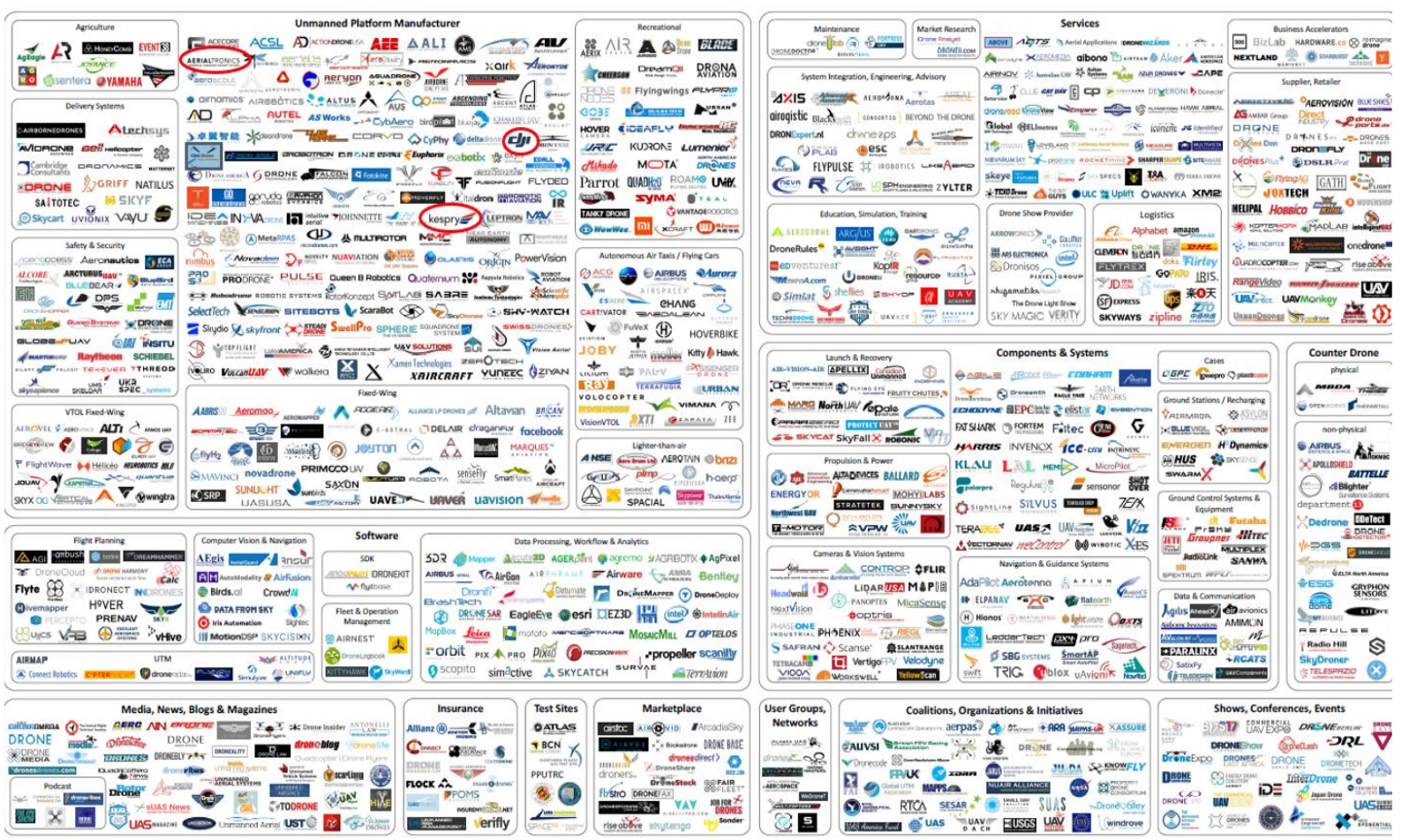

Figure 3. The Drone Market 2018, Manufactures, Softwares, Systems, Suppliers, Medias, Insurance.

\section{Methodology}

\subsection{Material and methods}

A sequence of tests has been carried out to investigate the potential and conditions with drones to replace or support some of the current preventive maintenance inspections and manual duties in the open pit. For the tests the following mining activities and areas were chosen: gas measurement after blasting, inspection of press filter area by flying in the concentrator silo and water pipes, inspection in flotation, primary mill section, crusher and the trolley line (electrified). Several of these are hard-to-reach areas that pose a danger and risk for an employee to inspect. In addition, maintenance personnel are transported with diesel-powered mining vehicles, a trip that can take up to 30 minutes to just travel from one side to the other of the open pit. During the inspections, the test; with the drones, aimed at investigating for example:

- Discolorations that could be a hint of rust on e.g. pipes in hard to reach areas in e.g. the flotation building

- Damage to the equipment and thus verify the need for spare part change

- Bolt movements
- Flying inspection with thermal camera of moving trucks to detect e.g. oil leakage or elevated engine temperatures, worn tires

A few drones were selected for the test, see Figure 4 - 7, and the features defined in Table 1, were evaluated when selecting proper drones. The selected drones had different or similar capacities to meet those demands.

Table 1. Drone requirements.

\begin{tabular}{|l|l|}
\hline \multicolumn{1}{|c|}{ Requirements } & \multicolumn{1}{c|}{ Comment } \\
\hline $\begin{array}{l}\text { Suitable for an open } \\
\text { pit operation }\end{array}$ & $\begin{array}{l}\text { It is a dirty and hazardous } \\
\text { environment. }\end{array}$ \\
\hline Battery solutions & $\begin{array}{l}\text { Some activities demand } \\
\text { that the drone can operate } \\
\text { for a longer sequence. }\end{array}$ \\
\hline $\begin{array}{l}\text { Temperature } \\
\text { resistant }\end{array}$ & $\begin{array}{l}\text { The weather can reach } \\
\text { minus } 30 \quad{ }^{\circ} \text { C or even } \\
\text { colder and snow. }\end{array}$ \\
\hline Payload capacity & $\begin{array}{l}\text { Different payload will be } \\
\text { attached for the different } \\
\text { inspection activities like } \\
\text { for example thermal } \\
\text { camera and gas sensor. }\end{array}$ \\
\hline Avoidance solutions & $\begin{array}{l}\text { Confined spaces will be } \\
\text { inspected }\end{array}$ \\
\hline
\end{tabular}




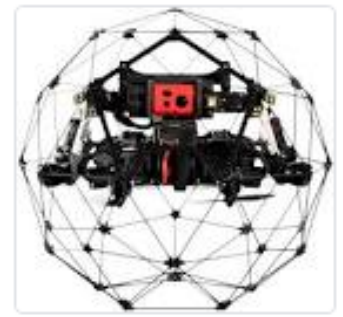

Figure 4. Flyability Elios 2.

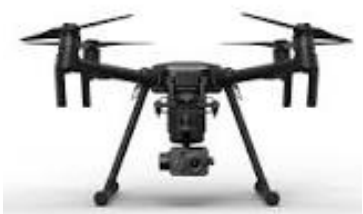

Figure 5. DJI Matrice 210 XT2.

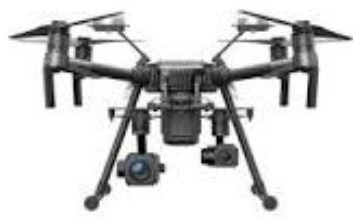

Figure 6. DJI Matrice 210 Z30.

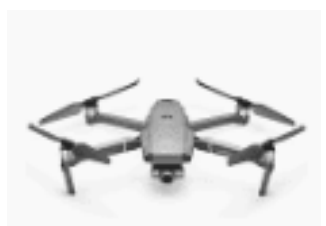

Figure 7. DJI Mavic 2 Zoom.

The Flyability Elios, Figure 4, was selected for inspecting places and objects where few or no inspections have been carried out in the past since some areas are difficult, or even impossible, to reach by a human or not secure enough. The advantage of this drone is that it is less sensitive to impact on the inspected areas, as the drone is encased in a steel structure.

\subsection{Theory}

This document aims to propose possible solutions that improve complex and time-consuming inspection processes with the goal to prevent dangerous situations, such as fires, from occurring. For achieving accurate and earlier discoveries of equipment deficiencies we introduce Bayesian Networks, BN, (Berthold et al., 1999), decision trees, for analysis of the trend (Craven, 1997) development of features and decision support.

Neural networks (McCulloch et al., 1943; Haykin, 1999) represent a brain metaphor that process information. The biological neuron ideates the elementary unit of any biological nervous system (McCulloch et al. 1943; Amit et al., 2003; Berthold et al., 1999; Zurada, 1992). They appear to be organized in structures where, after sufficient learning period, collaborate to solve a high number of complex tasks. Further neural computing refers to a pattern recognition (Tsai, 2009) methodology for machine learning (ML) where an artificial neural network (ANN) in Figure 8 is the resulting model from neural computing (McCulloch et al., 1943). Neural networks are programmed to:

- Store

- Recognize

- Associatively retrieve patterns or database entries

- To solve combinatorial optimizations problem

- To filter noise from measurement data

- To control ill-defined problems

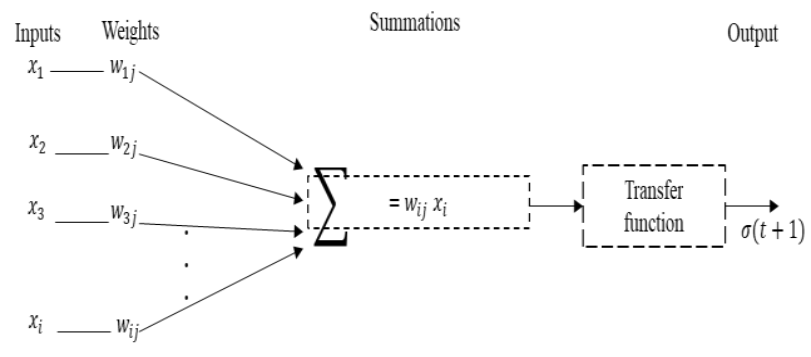

Figure 8 The artificial neuron.

Neural networks have gained eminent interest due to its forecasting applications, clustering and business classifications applications for prediction and pattern recognition in connection to their ability to "learn" from the data, their nonparametric nature (i.e., no rigid assumptions), and their capacity to generalize.

$$
\sigma(t+1)=f\left(\sum_{i=1}^{n} w_{i} x_{i}(t)\right)
$$

By training, the neural network method gradually calculates, equation (1) (including repeated iteration or cumulative calculation) the weights, $w_{i j}$, the neural network connected. In our study, the inputs, $x_{i j}$, are represented by the values from the signal gathered from the mining equipment's different sensors like. temperature and gases (hydrocarbons, NOx...) being attached e.g. to a mining vehicle but also on a drone where the temperature can be measured by the FLIR camera. Then combining the gathered input signals root cause analyses (RCA) can be carried out supported by a graphical structure of $\mathrm{BN}$ decision tree model as shown in Figure 9. 


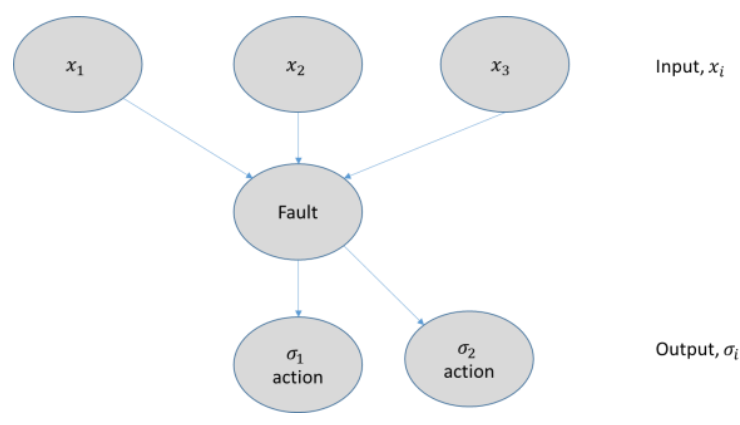

Figure 9. Decision Tree.

Neural networks have proved to be efficient to use for estimating sampled functions when we do not know the form of the function. The abilities, pattern recognition and function estimation constitute ANNs. It is a general methodology used for many functions, e.g. autonomous driving (Kasper et al., 2012) and process control (G. Weidl et al., 2005 and 2008, Abraham et al., pp. 221230, 2002) for condition monitoring, RCA and decision support of complex processes.

The gas tests carried out (Martinsen et al., 2019) showed possibilities to detect oil leakage, oil mist and risks for fires or toxic substances on mining vehicles before they cause harm. Different sensors detected hydrocarbons, NOx, high temperatures at "risk positions" both at vehicles and stationary. Some 20 different types of sensors were evaluated. To detect gases (Martinsen et al., 2020) at an early stage with adequate concentration the study showed the need to suck gas from critical positions, e.g. in the engine, close to hydraulics in the drilling machine or at the battery pack. PID (Photo Ionization detector) sensors detected most hydro carbons at a reasonable concentration (ppmrange) while IR detectors require higher concentrations. The FLIR thermal camera allows to detect increased temperatures but needs to be positioned towards "the problem area" (Martinsen et al., 2020). For detecting temperature changes, that can develop into a dangerous situation, it might not be a solution to attach several temperature sensors on a mining vehicle positing towards each possible problem area. Especially considering installation costs and the need for maintenance they might require. Therefore, drone inspections, with FLIR camera as a payload, has been tested at the open pit, in this research project to support early indication of increased temperature. In an underground mine the FLIR cameras could for instance be attached at the entrance and study the mining vehicles when they are going in and out of the mine. Combining machine data with signals from the sensors forms the basis for RCA and the development of decision trees. Covid-19 has forced us to postpone a number of test occasions at the Aitik site meaning some test data and results are missing. So, this paper is focusing on the methodology of decision trees.

\section{Results with discussions}

\subsection{Tests occasions}

A few drone test series have been carried out, initially to create an understanding of the drone's capacity with different payloads. The first test series concerned measuring of gases after blasting in normal weather conditions. The gas sensor attached to the drone had the functionality to measure multiple gases $\mathrm{CO}, \mathrm{NO}$ and $\mathrm{NO}_{2}$ and was of the same brand as the handheld sensor. This is a mandatory activity and according to the Swedish authorities (AFS, 2018) which has recently been updated, the gas levels it allows employees to be exposed for are listed in table $2 . \mathrm{KGV}$ is recommended maximum exposure value calculated as a time-weighted average over a reference period of 15 minutes. While NGV is the occupational exposure limits for one working day, normally 8 hours.

Table 2. Gas level according to the Swedish regulation.

\begin{tabular}{|l|c|c|}
\hline Gases & Level $(N G V)$ ppm & Level $(K G V) p p m$ \\
\hline $\mathrm{CO}$ & 20 & 100 \\
\hline $\mathrm{NO}$ & 2 & 0 \\
\hline $\mathrm{NO}_{2}$ & 0,5 & 1 \\
\hline
\end{tabular}

This activity is performed manually with a handheld sensor by the person in a vehicle who makes the first trip to the bottom of the pit, which takes about approximately thirty minutes to reach. Which is more time than the drone needed to measure the entire blasting area. If the level is not acceptable, they return to the top and wait a while before transporting themselves down to the pit to repeat the measurement. Not until acceptable levels are measured, the work can start to load the trucks with ore. The test observed that the drone was able to stay in the blasting area until acceptable gas level was measured. In Table 3, a fraction of all tests data is shown. The drone was situated at the same coordinates as the vehicle was driving to ensure we measured at the same place and at the same time.

Table 3. Some sample of gas measurement, manually vs drone mounted sensor in the north blasted area

\begin{tabular}{|c|c|c|}
\hline Sensor & $\begin{array}{c}\text { Handheld, } \\
\text { ppm }\end{array}$ & $\begin{array}{c}\text { Drone mounted, } \\
\text { ppm }\end{array}$ \\
\hline $\mathrm{CO}$ & 6 & 6 \\
\hline $\mathrm{NO}$ & 0 & 2,2 \\
\hline $\mathrm{NO}_{2}$ & 0,04 & 0,14 \\
\hline
\end{tabular}


The second test series was conducted during winter with a temperature of minus $35^{\circ} \mathrm{C}$. While third series of tests was conducted in heavy winds and rain. The drones used in the test showed almost problem-free regardless of weather conditions. Except in the very cold conditions when the wings froze, and we were forced to defrost. In Table 4, fraction of test data flying over the blasted area are shown. The indication is that measuring with a handheld sensor from the "road" will not capture the entire gas level situation.

Table 4. Some sample gas measurement, drone flight over blasted area, north.

\begin{tabular}{|l|c|}
\hline Sensor & Drone mounted, ppm \\
\hline $\mathrm{CO}$ & 84 \\
\hline $\mathrm{NO}$ & 8,5 \\
\hline $\mathrm{NO}_{2}$ & 0,18 \\
\hline
\end{tabular}

All three test sessions demonstrated the benefits of performing this type of work with a drone such as:

- The drone could fly over the whole blasting area compared to the vehicle that only could travel on the road, if it was navigable.

- Received more accurate data

- Replacing the vehicle with a drone will result in less $\mathrm{CO}_{2}$ and is thus more environmentally friendly.

- Inhalation of these gases can be dangerous for humans. It can block the transport of oxygen to the brain and you develop an irreversible medical condition. Some cases have gone to court that ended in conciliation. The tests show that it will be safer to carry out the measurement with a drone equipped with gas sensors.

- If the blasting map is fed to the drone, it can fly in an autonomous (Chen, 2018) manner over the exact area.

- Regardless of the gas levels, the drone can remain in the area and measure and record continuously.

- $\quad$ Replacing this manual task with a drone allows savings of up to one-man week per year.

Further, the FLIR camera mounted on the drone was tested. The FLIR camera measures "hot spots", the highest temperature in the image, and what this temperature is. It indicates where the risk of, for example, fire is greatest. With this it is possible to scan and find risk temperatures in a sophisticated way like in Figure 10, where leakage was detected during the flights. The temperature itself may not say much more than possibly elevated "hot spot" values, but if these data are correlated with machine data and the values from the gas data from the sensors mounted on the mining vehicle, it increases the chance of finding the fault that causes the situation. RCA with the support of decision trees (like e.g. in Figure 13-15) provide the opportunity for corrective measures to be proposed.

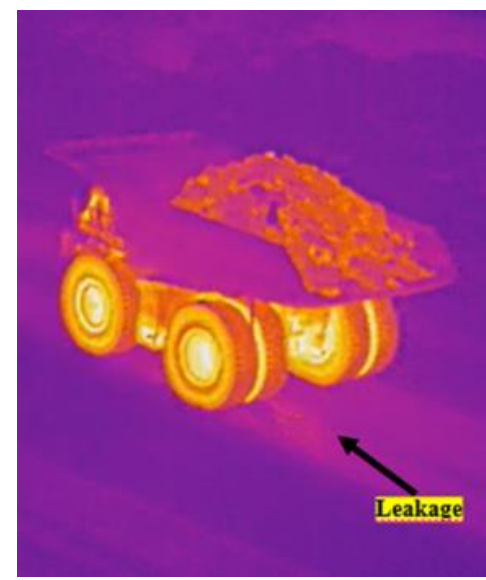

Figure 10. Leaking mining vehicle.

With a FLIR camera mounted on a drone, it supports inspections by scanning all mining equipment in the open pit area and allows it to be carried out on a more regular basis than today's. On a drilling rig, for example, it is interesting to follow temperatures on engines, hydraulics and oil leaks, etc. On a conveyor belt the test indicated possibilities for detection on e.g. worn bearings. For an underground mining the same camera could be mounted at the entrance and exit to the mine and measure the temperature of the brakes as for tires. With image and pattern recognition comparing with previous pictures increased temperature values could be detected and warn at an early stage. In addition, tests with drones were conducted in the flotation area, in the crusher and finally inspection of the electrified Trolley Line shown in Figure $11-13$.

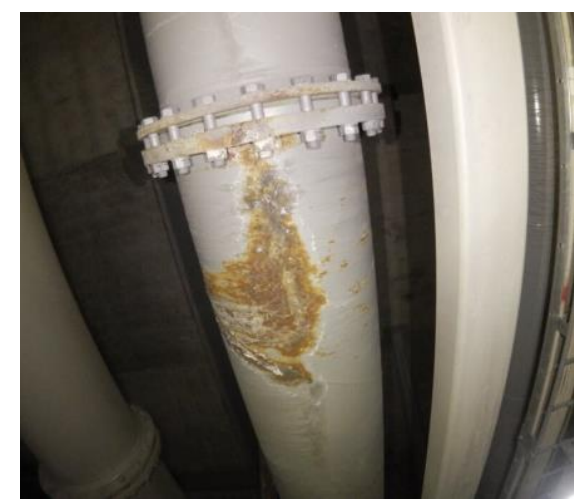

Figure 11. Flotation area, rusty pipe. 


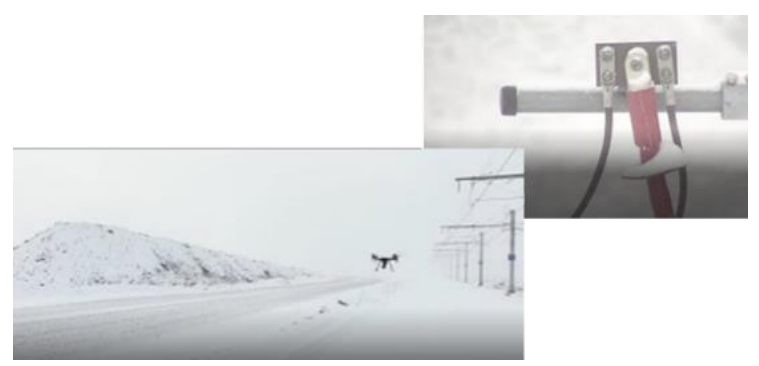

Figure 12. Trolley Line objects.

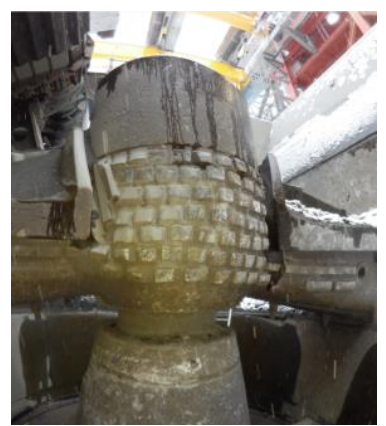

Figure 13. Crusher.

From the described tests the following benefits could be observed:

- Possible to inspect areas where safety of the employee cannot be guaranteed

- Reach areas that had never been inspected before

- $\quad$ Time saving

- The images that the camera took from the drone flights was possible to be viewed by several employees in a superior surveillance system room simultaneous, and thus support and streamlining the troubleshooting process when more than two eyes look at the problem.

\subsection{Decision Trees}

The above conducted tests show possibilities with both sensors and drones in the mining business. Increasing production will require several solutions that allow equal productivity to be maintained or even further improved. Using only drones and sensors is not the whole solution. It will be necessary to ensure that all collected data and images are processed in an efficient manner and communicated to an overall production and safety system so that warnings and alarms can be acted upon. A piece of the puzzle for transforming into autonomous mining operation decision trees for each aspect in the mining process is proposed to support monitoring and perceive changes in production more efficiently and for minimizing productions stops for maintenance. Some examples of decision trees can be seen in Figures 14-16.

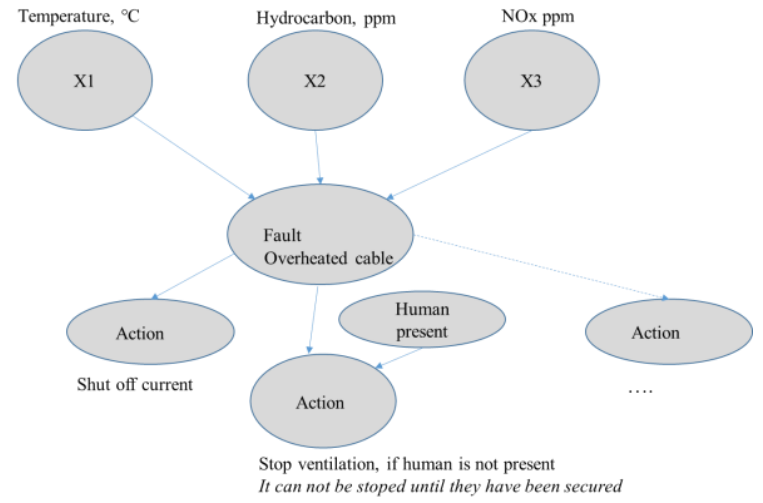

Figure 14. Decision tree for overheated cable.

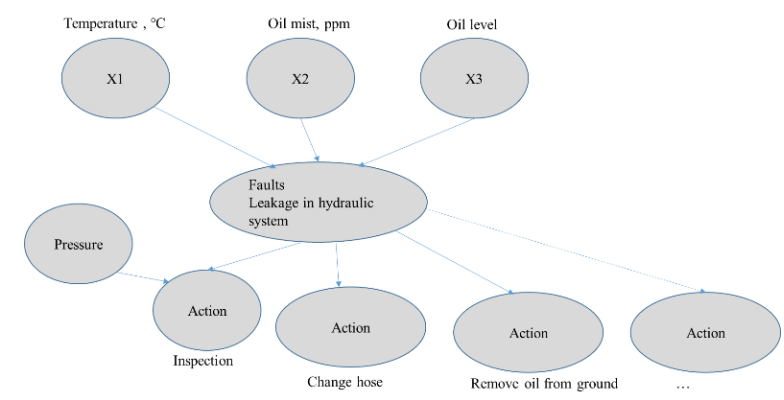

Figure 15. Decision tree for leakage in hydraulic system.

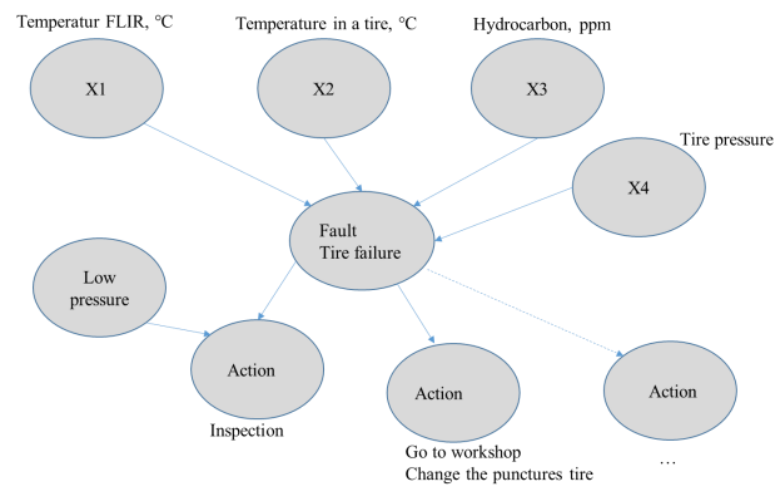

Figure 16. Decision tree for tire failure.

\section{Conclusions}

Future mining production is predicted to develop into fully autonomous mining processes. Safety and security will be important aspects in such operation. To be able and catch early changes in production predictive and proactive maintenance activities is preferred. Detecting changes in production that may cause a stop needs to be quicker than today. This requires sustainable solutions supported with smart inspections and early discovery of changes before the situation develops into a dangerous state. Today's maintenance inspections consist been verified that some of them could be supported with 
drones equipped with appropriate payloads. A compilation of the results from the drone tests have been presented including possible influence of the investigated parameters a decision trees methodology was introduced.

The results show that drones equipped with different payloads can support the conversion to succeed with autonomous mining concept and be the enabler for safer and efficient work methods, inspect parts in hard-toreach areas or not reachable for a human at all. But not least the possibility of reducing carbon dioxide emissions from transport by mining vehicles, powered by diesel, for inspections when they can be advantageously replaced by drones, possibly powered by batteries. Which in turn contributes to the goal that Sweden succeeds with the goal of becoming a fossil-free country by year 2045 .

A few decision trees were suggested in order to support the future development of an AI application that automatically suggests maintenance actions. The decision tree contributes to increased safety by minimizing time for conducting maintenance work in hard to reach areas and prevent dangerous situations from occurring. If the drone inspections can be initiated and monitored automatically via a central operating system and using autonomous routes, the conditions for a self-running inspection process can be created.

Future research activities will focus on diagnostic supported by deep learning, pattern recognition as for artificial intelligence applications. In addition, autonomous inspection routes will be evaluated. The authors believe that the use of machine learning and artificial intelligent application creates the conditions for reducing acute production stoppages and facilitates maintenance inspections and thus creates the conditions for productivity to be maintained or even more likely to improve as the production increases.

\section{Acknowledgements}

The Swedish Innovation Agency, Vinnova, RISE, Swedish Research Institute in Borås, Epiroc, $\mathrm{ABB}$ and Mälardalens University for their devoted support. Specially thanks to Aitik, Boliden for the opportunity to conduct the tests at their site. Finally, Scandinavia Drones for sharing and demonstrating their expertise.

\section{References}

A. Abraham et al. (Eds.), Soft Computing Systems - Design, Management and Applications, pp. 221-230. IOS Press, Amsterdam, the Netherlands, 2002.

Khajanchi Amit. Artificial Neural Networks. The next intelligence, 2003.

AFS. Arbetsmiljöverket. Hygienska gränsvärden; 2018:1

Michael Berthold and David J. Hand. Intelligent Data Analysis an introduction. Spinger-Verlag Berlin Heidelberg New York: Publishing, 1999.
Shihui Chen, Umut Durak, and Sven Hartmann. Modeling and Simulation-based Development of Autonomy Features for Drones, SNE 28(2):55-60, 2018. doi: 10.11128/ sne.28.tn.10413.

M. W. Craven and J. W. Shavlik. Using neural networks for data mining. Future Generation Computer Systems, 13:211-229, 1997.

W. S. McCulloch and W. Pitts. A logical calculus of the ideas immanent in nervous activity. Bulletin of Mathematical Biophysics, 5:115-133, 1943.

The Drone Market Report 2019-2024. Drone Insight Industry

Rickard Hansen. Design fires in underground hard rock mines, School of Sustainable Development of Society and Technology, Mälardalens University, Licentiate Thesis 127, Västerås, Sweden, 2011.

Rickard Hansen. Study of heat release rates of mining vehicles in underground hard rock mines, Mälardalens

University Press PhD Dissertation No. 178, Västerås, Sweden, 2015.

Rickard Hansen. Fire statistic from the mining industry in New South Wales, Queensland and Western Australia, The University of Queensland. doi:0.131340/ RG.2.2.22666.777 67, Australia, 2018.

S. Haykin. Neural Networks, Prentice Hall, 1999.

Dietmar Kasper, Galia Weidl, Thao Dang, Gabi Breuel, Andreas Tanmke, and Andreas Wedel. Object-Oriented Bayesian Network for Detection of Lane Change Maneuvers. IEEE Intelligent Transportation System Magazine, 2012.

Madeleine Martinsen, Erik Dahlquist, Anders Lönnermark and Örjan Säker. Gas sensors for early detection of fire hazards caused by vehicles in underground mines. International Conference on Scandinavia Society, SIMS 2019. Aug 1316, 2019, Västerås, Sweden. Paper ID: 28.

Madeleine Martinsen, Erik Dahlquist, Anders Lönnermark, and Örjan Säker. Energy and Safety Diagnostic in Underground Facilities. Conference paper ISTSS Munich, March 2020.

Yichang (James) Tsai, Using Image Pattern Recognition Algorithms for Pressing Video Log Images to Enhance Roadway Infrastructure Data Collection. Final Report for Highway IDEA Project 121, 2009.

G. Weidl, A.L. Madsen, and S. Israelson, Applications of object-oriented Bayesian networks for condition monitoring, root cause analysis and decision support on operation of complex continuous processes, Computers and Chemical Engineering, 29: 19962009, 2005.

G. Weidl, A. L. Madsen, and E. Dahlquist. Condition monitoring, Root Cause Analysis and Decision Support on Urgency of Actions. In Book Series FAIA (Frontiers in Artificial Intelligence and Applications), vol. 87.

G. Weidl, A. Madsen, and E. Dahlquist. Decision support on complex industrial process operations. pages 313328, In O. Pourret, P. Naim, and B. Marcot, editors, Bayesian Networks, a practical guide for applications. John Wiley. ISBN 978-0-470-06030-8, 2008.

J. M. Zurada. An introduction to artificial neural networks systems. St. Paul: West Publishing, 1992. 